\title{
Jaagsiekte sheep retrovirus detected in human lung cancer tissue arrays
}

\author{
Nicolle M Linnerth-Petrik', Scott R Walsh', Paul N Bogner ${ }^{2}$, Carl Morrison² and Sarah K Wootton ${ }^{1 *}$
}

\begin{abstract}
Background: Adenocarcinoma is the most common type of non-small cell lung cancer and is frequently observed in non-smoking patients. Adenocarcinoma in-situ (formerly referred to as bronchioloalveolar carcinoma) is a subset of lung adenocarcinoma characterized by growth along alveolar septae without evidence of stromal, vascular, or pleural invasion, that disproportionately affects never-smokers, women, and Asians. Adenocarcinoma in-situ is morphologically and histologically similar to a contagious lung neoplasm of sheep called ovine pulmonary adenocarcinoma (OPA). OPA is caused by infection with the exogenous betaretrovirus, jaagsiekte sheep retrovirus (JSRV), whose envelope protein (Env) is a potent oncogene. Several studies have reported that a proportion of human lung adenocarcinomas are immunopositive for an antigen related to the Gag protein of JSRV, however other groups have been unable to verify these observations by PCR.
\end{abstract}

Methods: Here we examine human lung cancer tissue arrays (TA) for evidence of JSRV Env protein and DNA by immunohistochemical staining and PCR, respectively.

Results: Our results reveal that a subset of human lung cancers express an antigen that reacts with a JSRV Env-specific monoclonal antibody in immunohistochemistry and that exogenous JSRV-like env and gag sequences can be amplified from TA tumor samples, albeit inefficiently.

Conclusions: While a causative role has not been established, these data suggest that a JSRV-like virus might infect humans. With next generation sequencing approaches, a JSRV-like virus in human lung cancers may be identified which could have profound implications for prevention, diagnosis and therapy.

Keywords: Lung cancer, Bronchioloalveolar carcinoma, Ovine pulmonary adenocarcinoma, Jaagsiekte sheep retrovirus, Immunohistochemistry, PCR, Tissue microarray

\section{Background}

Lung cancer remains the leading cause of cancer related deaths worldwide with a 5-year survival rate for all stages combined of only $16 \%$ [1]. Lung cancer can be broadly divided into two groups; non-small cell lung cancer (NSCLC) and small cell lung cancer (SCLC). Pulmonary adenocarcinoma is the most prevalent NSCLC in both men and women [2]. Bronchioloalveolar carcinoma (BAC) is a subtype of pulmonary adenocarcinoma that often presents as multifocal lesions in the peripheral regions of the lung with a "ground glass" appearance by radiologic imaging. It is defined histologically by a pure lepidic growth pattern with neoplastic cells growing on preserved alveolar walls with

\footnotetext{
* Correspondence: kwootton@uoguelph.ca

${ }^{1}$ Department of Pathobiology, Ontario Veterinary College, University of Guelph, Guelph, Ontario N1G 2W1, Canada

Full list of author information is available at the end of the article
}

no evidence of stromal, vascular or pleural invasion [3,4]. A recent consensus classification system for adenocarcinoma, in fact, has proposed replacement of the term BAC with "adenocarcinoma in-situ" [5]. These non-invasive lung lesions are more commonly found in non-smokers, women and the Asian population [6].

The main risk factors for lung cancer include cigarette smoke, asbestos, environmental pollution and radiation [7-10]. However, approximately $15 \%$ of all lung cancer cases are not attributable to any of these risk factors. It has been estimated that $15-25 \%$ of human cancer may have a viral etiology and two viruses in particular, the human papilloma virus (HPV) and jaagsiekte sheep retrovirus (JSRV), have been speculated to play a role in the pathogenesis of human lung cancer [11].

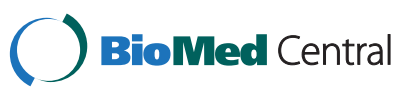

(c) 2014 Linnerth-Petrik et al.; licensee BioMed Central Ltd. This is an Open Access article distributed under the terms of the Creative Commons Attribution License (http://creativecommons.org/licenses/by/2.0), which permits unrestricted use, distribution, and reproduction in any medium, provided the original work is properly credited. 
JSRV is the causative agent of ovine pulmonary adenocarcinoma (OPA) [12], a disease characterized by the induction of a low grade multifocal mixed adenocarcinoma with papillary and/or acinar characteristics within the distal lungs of infected sheep. OPA shares clinical and histologic features with human adenocarcinoma in-situ and is regarded as a valuable large animal model for this human disease [13-15]. The cellular receptor for JSRV is the glycosyl-phosphatidylinositol (GPI)-linked protein, hyaluronidase 2 (Hyal2) [16]. Hyal2 homologues from a variety of different species, including humans, have been shown to mediate entry of JSRV Env pseudotyped retroviral particles [17]. JSRV induces lung tumors in sheep through expression of the envelope (Env) protein [18]. Several studies have shown that the JSRV Env protein has the ability to transform a variety of cell types in vitro [19-21], including human cells [22], and can induce lung tumors in mice $[23,24]$. However, the exact mechanism by which Env mediates tumorigenesis is still unknown.

The ability of JSRV to cause peripheral lung tumors in sheep with clinical and histological similarities to those frequently found in human lung adenocarcinoma [13-15], the capacity for JSRV to use the human homolog of Hyal2 to enter human cells $[16,25]$, and the fact that JSRV Env can transform human lung epithelial cells in vitro [22] has led to speculation that JSRV could be linked to a subset of human lung cancers [11]. Indeed, studies have detected JSRV capsid protein as well as orf- $x$, gag and endogenous JSRV sequences in human tissues [26-28]; however, there is no clear consensus on the association of JSRV with human lung cancer as other studies report no correlation between JSRV and human lung cancer [29-31]. Interestingly, a number of epidemiological studies have found that workers in abattoirs and meat processing plants have an increased risk of developing lung cancer that is postulated to be due to exposure to oncogenic viruses of food animals such as JSRV and bovine papilloma virus [32-34].

Given that JSRV Env is capable of inducing tumors in both sheep and mice, and due to the controversy surrounding the role of JSRV in human lung cancer, we decided to examine multiple types of human lung tumor samples for the presence of JSRV Env by immunohistochemical staining of lung cancer tissue arrays with an Env-specific monoclonal antibody and by PCR amplification with env- and gag-specific primers. Here we demonstrate that a subset of human lung cancers express an antigen that reacts with a JSRV Env monoclonal antibody and that env and gag sequences can reproducibly be amplified from genomic DNA extracted from human lung cancer tissue arrays, albeit inefficiently.

\section{Methods}

\section{Tissue samples}

Human lung cancer tissue arrays (LC2085a) containing lung tumors from 188 patients and 20 samples of normal tissue were purchased from US Biomax (Rockville, MD). Of the 208 core tissues, there were 72 adenocarcinomas, 72 squamous cell carcinomas, 22 small cell carcinomas, 2 large cell carcinomas, 10 normal lung tissues and 10 normal adjacent tissues. A human nasopharyngeal cancer tissue array (NH1001, US Biomax) containing 15 squamous cell carcinomas, 3 basal cell carcinomas, 2 adenocarcinomas, 15 papillomas, 6 polyps, 3 each of hyperplasia and inflammation and 1 adjacent normal tissue was used as a control. Note that all specimens on the lung and nasopharyngeal cancer tissue arrays were of Chinese origin. In addition, 10 examples of adenocarcinoma in-situ and 10 non-neoplastic lung tissue specimens (unstained slides and tissue cores) were obtained from formalin fixed paraffin embedded tissue blocks at the Roswell Park Cancer Institute (Buffalo, NY). Approval for the use of human tissue samples was obtained from the Roswell Park Cancer Institute. Tissue arrays were subjected to immunohistochemical analysis as described below.

\section{Cell lines}

Human A549 cells (ATCC CRL-1573) and the ovine pulmonary adenocarcinoma cell line, JS7, (kindly provided by Dr. Mark Ackerman, Iowa State University, USA) were propagated in Dulbecco's modified Eagle medium supplemented with $10 \%$ fetal bovine serum, $2 \mathrm{mM}$ L-glutamine and $1 \%$ penicillin/streptomycin. HBE135-E6E7 cells (ATCC CRL-2741) were grown in keratinocyte-serum free medium (Invitrogen) with $5 \mathrm{ng} / \mathrm{ml}$ human recombinant EGF and $0.05 \mathrm{mg} / \mathrm{ml}$ bovine pituitary extract. Cells were maintained at $37^{\circ} \mathrm{C}$ in $5 \% \mathrm{CO}_{2}$.

\section{Immunohistochemistry}

Paraffin embedded tissue was dewaxed and rehydrated using xylene followed by decreasing concentrations of ethanol. Citrate buffer was used for antigen retrieval and tissues were blocked using $5 \%$ bovine serum albumin (BSA). Tissue sections were incubated at $4^{\circ} \mathrm{C}$ overnight with either a 1:50 dilution of a highly specific anti-JSRV Env monoclonal antibody [35], an isotype control antibody or supernatant from an unrelated antibody-producing hybridoma as described previously [36]. Primary antibodies were detected using a 1:50 dilution of an anti-mouse secondary antibody conjugated to biotin (Santa Cruz Technologies). Sigma Fast 3,3-diaminobenzidine tablets (Sigma, St. Louis, MO) were used to visualize protein localization in the tissue. Hemotoxylin was used as a counterstain. Tissues were analyzed by three independent observers and were graded as 0 for no staining, 1 for low intensity staining, 2 for moderate intensity staining in $>10 \%$ of tissue or high intensity staining in $<10 \%$ of tissue, and 3 for high intensity staining in $>10 \%$ of tissue.

To confirm the specific reactivity of the anti-JSRV Env monoclonal antibody on histology sections, a peptide 
blocking technique was employed [37]. The peptide used in this assay was a fusion protein called JSU-IgG which is comprised of the JSRV Env surface domain (SU) fused to the human immunoglobulin G (IgG) constant region [38]. JSU-IgG was used to boost mice during the preparation of mouse hybridomas producing antibodies specific for the JSRV Env SU domain [35]. The anti-JSRV Env monoclonal antibody was neutralized by incubating with an excess of JSU-IgG (1:5 and 1:10 ratios) for 1 hour at room temperature, followed by the standard immunohistochemistry procedure described above. A JSU-IgG alone control was also performed.

\section{Genomic DNA extraction}

Three serial sections of a human lung cancer tissue array were purchased and processed individually such that all of the tissues on one array (excluding normal tissue) were pooled together giving a total of three pooled tissue array samples, TA\#1, TA\#2 and TA\#3, one for each array. Tissue array slides ( 3 in total) were first dewaxed in xylene for 30 minutes followed by rehydration of the tissues for 30 minutes each in 100\% ethanol, 95\% ethanol, and 70\% ethanol. The slides were then washed with PBS for 15 minutes before tissue was scraped from the slides, pooled together and placed into $200 \mathrm{ul}$ of PBS. Note that it was necessary to pool all of the tissue samples on the array in order to obtain sufficient genomic DNA for PCR analysis. Genomic DNA was extracted from tissue arrays, tissue cores and cell lines using the QIAamp DNA mini kit (Qiagen) in accordance with the manufacturer's instructions.

\section{PCR detection of env and gag sequences}

JSRV env and gag sequences were detected by PCR amplification using 100-300 ng of genomic DNA and either env (5'-ATACGGGAACGGATCTGGACC-3' and 5'-CAACATGAATGGATACGGCACGC-3') or gag (5'-C CCCATCTCTGAAAATGCAC-3' and 5'-TGTTTAGACG GTGGAGGAAA-3') specific primers which amplify 382 and 313 base pair (bp) fragments, respectively. Primers were designed according to the JSRV genomic sequence with accession number AF105220. DNA template integrity was assessed in a separate PCR reaction using GAPDH specific primers (5'-CCACCCATGGCAAATTCCATGG CA-3' and 5' -TCTAGACGGCAGGTCAGGTCCACC-3') which give rise to a $593 \mathrm{bp}$ PCR product. For PCR amplification, the 5PRIME MasterMix was employed and the cycling conditions were as follows: $94^{\circ} \mathrm{C}$ for 2 min followed by 30 cycles of $94^{\circ} \mathrm{C}$ for $30 \mathrm{~s}, 55^{\circ} \mathrm{C}$ for $30 \mathrm{~s}$ and $65^{\circ} \mathrm{C}$ for $2 \mathrm{~min}$. A final extension of $7 \mathrm{~min}$ at $65^{\circ} \mathrm{C}$ concluded the program. PCR products were purified with the QIAquick Gel Extraction Kit (Qiagen). Purified PCR products were cloned into the pGEM-T Easy vector (Promega) following the manufacturer's instructions and purified plasmid DNA (where possible, 3 clones per sample) was sequenced two times in both directions with an ABI Prism DNA Sequencer.

Several measures were taken to avoid contamination. All experiments were conducted at the beginning of the day in a laboratory located in a separate building that had not previously housed JSRV DNA or ovine tissue. DNA extractions and PCR amplifications were conducted using previously unopened tissue arrays, primers, DNA extraction kits, PCR amplification reagents and filtered tips.

\section{PCR detection of ovine genomic DNA}

To test whether fragments of sheep DNA were present in the human DNA samples used in this study, a nested PCR assay was employed using published primers (mt1f; $5^{\prime}$-TA TAGTAGGAACCGCCTTAAGCCTA-3', mt2f; 5' -TACT CGGAGATGACCAAATCTACAACG-3', mt3r; 5' -ATTC AGGTTTCGGTCCGTTAGTAGTATTG-3', mt4r; 5' -TA CTTCAGGGTGCCCAAAGAATCAGAATAG-3') specific for sheep mitochondrial cytochrome-coxidase subunit 1 [27].

\section{Results}

\section{Detection of JSRV Env protein in human lung cancer tissue arrays}

To evaluate the association between JSRV Env and human lung cancer, three sections of a human lung cancer tissue array purchased from US Biomax were analyzed by immunohistochemical staining using an anti-JSRV Env monoclonal antibody [35]. Staining, which was observed in a subset of the samples (Figure 1), was confined to epithelial cells within the tumor and varied from apical (Figure 1E) to cytoplasmic (Figure 1F). Serial sections of the lung cancer tissue array were further analyzed by immunohistochemistry using an isotype control (Figure $1 \mathrm{G}$ and $\mathrm{J}$ ) as well as supernatant from an unrelated antibody-producing hybridoma (Figure $1 \mathrm{H}$ and $\mathrm{K}$ ) to control for non-specific staining. In both cases, no positive staining was observed.

Staining intensity of the JSRV Env antibody was quantified by three individuals according to the grading scheme described earlier and illustrated in Figure 1A, B, C and D. Immunohistochemical staining with the JSRV Env specific monoclonal antibody yielded the following results. $21 \%$ of adenocarcinomas and squamous cell carcinomas were positive according to our criteria (grade 2 or higher), of which $2 \%$ of adenocarcinoma and $4 \%$ of squamous cell carcinomas were highly positive (grade 3 ) (Table 1). It should be noted that with the small number of tumor biopsies that stained highly positive (8/187 squamous cell carcinomas and 4/207 adenocarcinomas), it is unlikely that there is any statistically significant difference between adenocarcinoma and squamous cell carcinomas. Conversely, only $5 \%$ small cell carcinomas stained positive for JSRV Env. 100\% of both normal tissue and adjacent normal tissue had either no staining or low intensity staining (Table 1). 

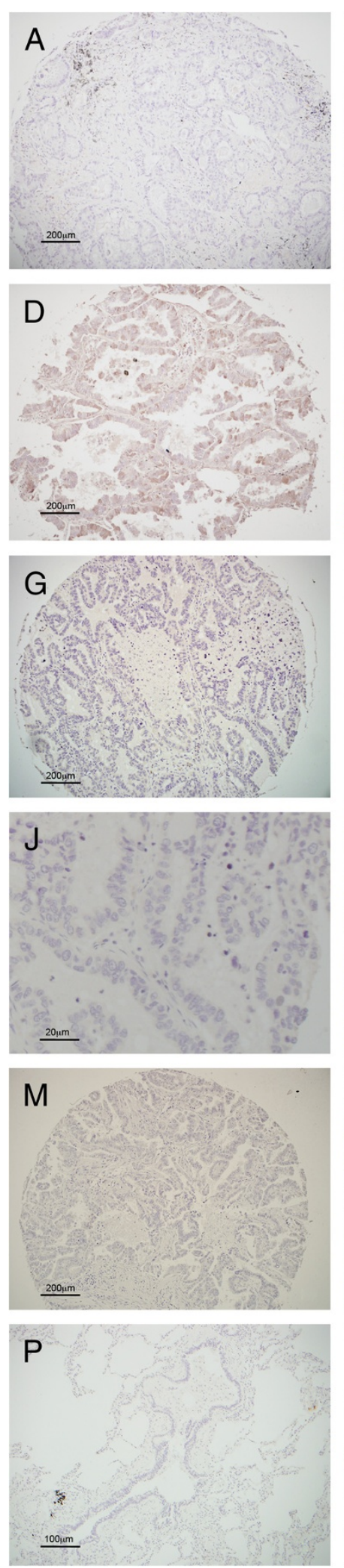

Figure 1 (See legend on next page.)
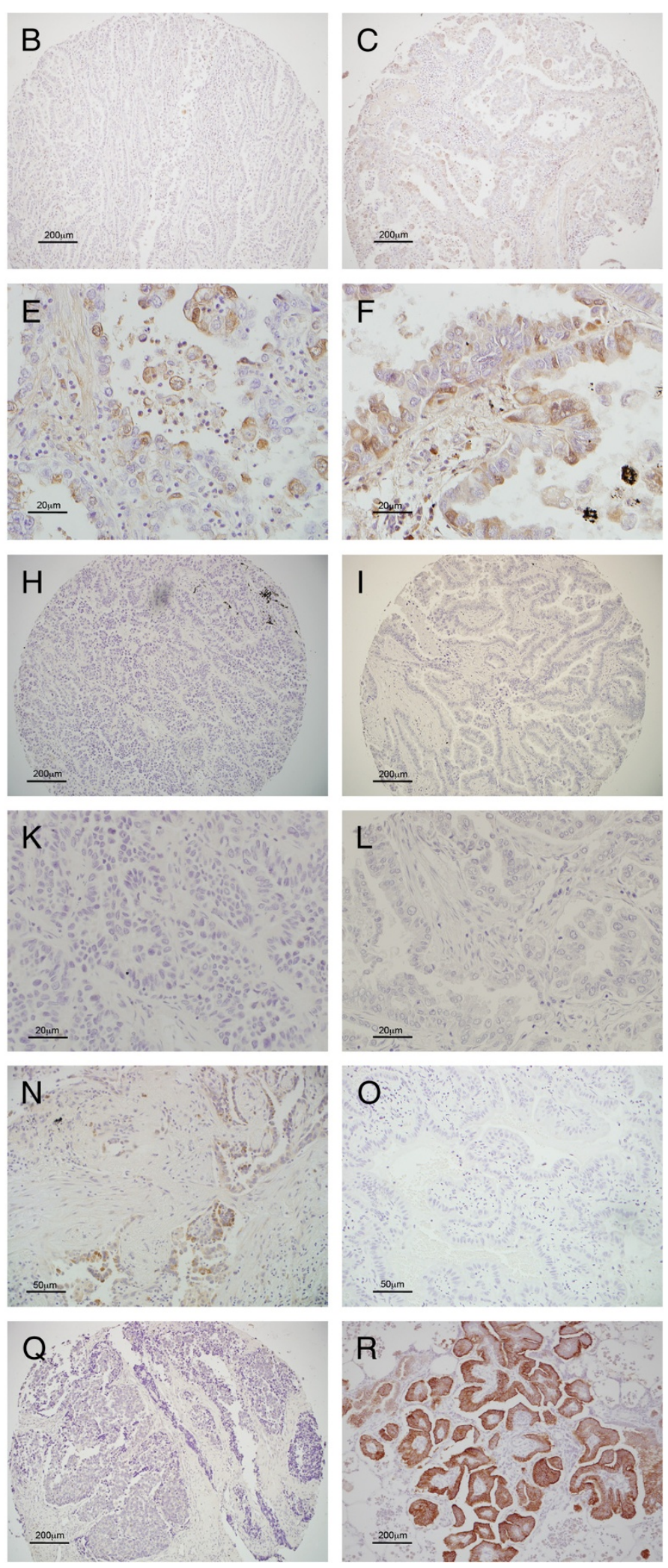
(See figure on previous page.)

Figure 1 Representative images of immunohistochemical staining of tissues with a monoclonal antibody against the JSRV Env protein. Human lung tumor tissue array samples representing grade 0 staining (A), grade 1 staining (B), grade 2 staining (C), and grade 3 staining (D). High magnification (40x) images of human lung tumors with grade $2(\mathbf{E})$ and grade $3(\mathbf{F})$ staining. Low $(4 X)$ and high (40X) magnification images of human lung tumor tissue array sample stained with an isotype control ( $\mathbf{G}$ and $\mathbf{J}$ ) and an unrelated antibody-producing hybridoma (H and $\mathbf{K}$ ). Lack of immunohistochemical staining of human lung tumor tissue arrays in the presence of JSRV Env antibody plus purified JSU-lgG protein

(I and L) or JSU-IgG protein alone (M). Human adenocarcinoma in-situ displaying clusters of JSRV Env positive cells (N). Representative images of human adenocarcinoma in-situ (0) and non-neoplastic human lung tissue (P) with no detectable Env staining. Nasopharyngeal carcinoma tissue array showing no detectable Env staining (Q). Lung tissue from an OPA affected sheep stained with the JSRV Env monoclonal antibody (R).

The extent of JSRV Env staining was further examined in the adenocarcinoma and squamous cell carcinoma tissues with respect to stage of disease. For stage I, II and III adenocarcinoma, $17 \%, 21 \%$, and $25 \%$ of tissue samples, respectively, were graded as 2 or higher (Table 2). Conversely, for stage I, II and III squamous cell carcinoma, 26\%, 19\%, and $20 \%$ of tissue samples, respectively, were graded as 2 or higher (Table 3). These results suggest that a subset (approximately 21\%) of human lung adenocarcinoma and squamous cell carcinoma tissues express an antigen that cross-reacts with the JSRV Env-specific monoclonal antibody and that in the case of adenocarcinoma, increased staining intensity correlates with more advanced stage cancer, whereas decreased staining intensity correlates with more advanced stage cancer in the case of squamous cell carcinoma. Moreover, there was no apparent relationship between positive staining with the JSRV Env monoclonal antibody and adenocarcinomas as the small percentage of squamous cell carcinomas that stained strongly positive (4\%) was twice that of strongly positive adenocarcinomas (2\%).

Given the histological and clinical similarities between OPA and the adenocarcinoma in-situ form of human lung adenocarcinoma, we decided to further evaluate JSRV Env staining in ten adenocarcinoma in-situ samples and 10 non-neoplastic lung tissue samples obtained from the Roswell Park Cancer Institute in Buffalo, NY. Immunohistochemical analyses revealed positive staining in 2 out of 10 adenocarcinoma in-situ samples (Figure $1 \mathrm{~N}$ ), while all of the remaining adenocarcinoma in-situ samples (Figure 1O) and non-neoplastic tissues (Figure 1P) were negative.
Since there have been no reports of ovine betaretroviral antigen or proviral DNA detection in nasopharyngeal carcinomas from human patients, we decided to use two nasopharyngeal carcinoma tissue arrays, produced by the same company that made the lung cancer tissue arrays, as additional controls. Unlike the human lung cancer tissue arrays, there was no detectable staining in the nasopharyngeal carcinoma tissue arrays (Figure 1Q) further suggesting that the positive staining on the lung cancer tissue arrays was indeed specific.

\section{Amplification of JSRV env and gag sequences from genomic DNA isolated from human lung cancer tissue arrays}

To verify the immunohistochemistry results, genomic DNA was isolated from three independent serial sections of a human lung cancer tissue array and one nasopharyngeal carcinoma tissue array produced by US Biomax as well as from ten adenocarcinoma in-situ and ten nonneoplastic tissue cores. In addition, genomic DNA was extracted from two human lung tumor cell lines (A549, H358) and one immortalized human bronchial epithelial cell line (HBE135-E6E7). Genomic DNA from the OPA derived lung tumor cell line, JS7 was used as a positive control and genomic DNA isolated from ten normal sheep lungs was used as a negative control. See Table 4 for a summary of all samples analyzed. Note that aside from the OPA sample, all genomic DNA extractions and PCR reactions were conducted in a separate building detached from our laboratory to avoid the potential for contamination. Using primers specific for exogenous JSRV env, products of the expected size (382 bp) were amplified specifically

Table 1 Total JSRV envelope staining of human lung tumor tissue arrays

\begin{tabular}{lcccc}
\hline & \multicolumn{4}{c}{ Staining intensity* } \\
\cline { 2 - 5 } Lung tissue & $\mathbf{0}$ & $\mathbf{1}$ & $\mathbf{2}$ & $\mathbf{3}$ \\
\hline Adenocarcinoma & $43 / 207(21 \%)$ & $120 / 207(58 \%)$ & $40 / 207(19 \%)$ & $4 / 207(2 \%)$ \\
Squamous cell carcinoma & $39 / 187(21 \%)$ & $108 / 187(58 \%)$ & $32 / 187(17 \%)$ & $8 / 187(4 \%)$ \\
Small cell carcinoma & $45 / 64(70 \%)$ & $16.64(25 \%)$ & $3 / 64(5 \%)$ & $0 / 64(0 \%)$ \\
Adjacent normal tissue & $39 / 46(58 \%)$ & $7 / 46(15 \%)$ & $0 / 46(0 \%)$ & $0 / 64(0 \%)$ \\
Normal lung tissue & $43 / 52(83 \%)$ & $9 / 52(17 \%)$ & $0 / 52(0 \%)$ & $0 / 52(0 \%)$ \\
\hline
\end{tabular}

*Tissues were graded as 0 for no staining, 1 for low intensity staining, 2 for moderate intensity staining in $>10 \%$ of tissue or high intensity staining in $<10 \%$ of tissue, and 3 for high intensity staining in $>10 \%$ of tissue. 
Table 2 Total JSRV envelope staining in adenocarcinomas based on stage

\begin{tabular}{lcccc}
\hline & \multicolumn{4}{c}{ Staining intensity* } \\
\cline { 2 - 5 } Stage & $\mathbf{0}$ & $\mathbf{1}$ & $\mathbf{2}$ & $\mathbf{3}$ \\
\hline $\mathbf{I}$ & $14 / 54(26 \%)$ & $31 / 54(57 \%)$ & $8 / 54(15 \%)$ & $1 / 54(2 \%)$ \\
II & $21 / 93(23 \%)$ & $52 / 93(56 \%)$ & $18 / 93(19 \%)$ & $2 / 93(2 \%)$ \\
III & $8 / 60(13 \%)$ & $37 / 60(62 \%)$ & $14 / 60(23 \%)$ & $1 / 60(2 \%)$ \\
\hline
\end{tabular}

*Tissues were graded as 0 for no staining, 1 for low intensity staining, 2 for moderate intensity staining in $>10 \%$ of tissue or high intensity staining in

$<10 \%$ of tissue, and 3 for high intensity staining in $>10 \%$ of tissue.

from DNA extracted from the lung tumor tissue arrays, albeit at very low levels (representative gel; Figure 2A upper panel, lane 2). A second round of PCR resulted in a much stronger signal (Figure 2A upper panel, lane 3). No PCR products were amplified from the human cell lines, the nasopharyngeal carcinoma tissue array, the non-neoplastic tissue, or normal sheep lung even after a second round of PCR (Figure 2A upper panel, lanes 4, 5,6, 8 and 10). First round PCR products amplified from the genomic DNA of three separate lung cancer tissue arrays were cloned. Sequence analysis of three independent clones revealed that these PCR products were $99-100 \%$ identical to that of the exogenous JSRV env sequence deciphered by DeMartini $e t$ al [39]; accession number AF357971 (Figure 2B). The JSRV env-like sequence amplified from two out of the three tissue arrays differed by a single nucleotide located within the surface domain (Figure 2B) and in one instance, this polymorphism resulted in an amino acid change from asparagine to aspartic acid (Figure 2C). Amplification of JSRV env sequence from the two Roswell Park Cancer Institute adenocarcinoma in-situ tissues that were positive by immunohistochemistry (\#2 and \#9) was not reproducible in that only 1 out of 3 PCR reactions resulted in a product of the expected size and despite multiple attempts, these products could not be cloned (data not shown).

To confirm that the anti-JSRV Env antibody was specific and without cross-reactivity, additional tissue arrays were tested by peptide neutralization using purified JSUIgG [38]. Immunohistochemistry was done as before, with the exception that slides were incubated with JSRV Env antibody + purified JSU-IgG protein or JSU-IgG

Table 3 Total JSRV envelope staining in squamous cell carcinomas based on stage

\begin{tabular}{lcccc}
\hline & \multicolumn{4}{c}{ Staining intensity* } \\
\cline { 2 - 5 } Stage & $\mathbf{0}$ & $\mathbf{1}$ & $\mathbf{2}$ & $\mathbf{3}$ \\
\hline I & $9 / 38(24 \%)$ & $19 / 38(50 \%)$ & $7 / 38(18 \%)$ & $3 / 38(8 \%)$ \\
II & $16 / 94(17 \%)$ & $60 / 94(64 \%)$ & $14 / 94(15 \%)$ & $4 / 94(4 \%)$ \\
III & $14 / 54(26 \%)$ & $29 / 54(54 \%)$ & $10 / 54(18 \%)$ & $1 / 54(2 \%)$ \\
\hline
\end{tabular}

*Tissues were graded as 0 for no staining, 1 for low intensity staining, 2 for moderate intensity staining in $>10 \%$ of tissue or high intensity staining in $<10 \%$ of tissue, and 3 for high intensity staining in $>10 \%$ of tissue.
Table 4 Summary of PCR results

\begin{tabular}{lccc}
\hline Specimen & $\begin{array}{c}\text { Number } \\
\text { analyzed }\end{array}$ & $\begin{array}{c}\text { Amplicon with } \\
\text { env primers }\end{array}$ & $\begin{array}{c}\text { Amplicon with } \\
\text { gag primers }\end{array}$ \\
\hline $\begin{array}{l}\text { Human lung cancer } \\
\text { tissue array }\end{array}$ & 3 & $3 / 3$ & $1 / 3$ \\
$\begin{array}{l}\text { Human nasopharyngeal } \\
\text { carcinoma tissue array }\end{array}$ & 1 & $0 / 1$ & $0 / 1$ \\
$\begin{array}{l}\text { Human lung tumor } \\
\text { cell line }\end{array}$ & 3 & $0 / 3$ & $0 / 3^{\mathrm{a}}$ \\
$\begin{array}{l}\text { Human adenocarcinoma } \\
\text { in-situ }\end{array}$ & 10 & $2 / 10^{\mathrm{b}}$ & $1 / 10$ \\
$\begin{array}{l}\text { Human non-neoplastic } \\
\text { lung tissue }\end{array}$ & 10 & $0 / 10$ & $0 / 10$ \\
\begin{tabular}{l} 
Normal sheep lung \\
\hline
\end{tabular} & 10 & $0 / 10$ & $0 / 10$ \\
\hline
\end{tabular}

aPCR products of the correct size were amplified but did not contain gag sequence.

${ }^{\mathrm{D} P C R}$ product amplified in only 1 out of 3 attempts.

protein. The positive staining seen in Figure 1D was blocked by the added JSU-IgG (Figure 1I and L) and no staining was seen with the JSU-IgG alone (Figure 1M).

Next we attempted to amplify part of the gag sequence from a relatively conserved region of the JSRV genome. Although DNA from all three tissue arrays and both adenocarcinoma in-situ samples produced a PCR product of the appropriate size using gag-specific primers, only the product from one of the three tissue arrays and one of the two adenocarcinoma in-situ samples was successfully cloned. Interestingly, while we were not able to clone env DNA from the adenocarcinoma in-situ samples, we were able to clone gag DNA. Sequence alignment with JSRV gag from sheep tumors identified a single nucleotide difference in the matrix region just upstream of variable region 2 [42] in both the tissue array and adenocarcinoma in-situ DNA (Figure 2D). In the case of the tissue array sequence, this nucleotide difference would result in a single amino acid substitution of an asparagine for a serine (Figure 2E). Although we observed bands of the expected size in the human lung tumor cell lines (Figure 2A middle panel, lanes 4-6), sequence analysis failed to reveal the presence of JSRV-like gag sequence.

\section{Sheep mitochondria DNA was not detected in human genomic DNA samples}

To rule out the possibility that the human genomic DNA samples that were positive for JSRV env and gag sequences were contaminated with sheep DNA, we screened human DNA samples for the presence of sheep DNA using primers specific for the sheep mitochondrial cytochromeoxidase subunit as described previously [27]. To determine the sensitivity of the assay, serial dilutions of normal sheep lung DNA were subjected to first round PCR followed by nested PCR. The first round of PCR was able to detect sheep genomic DNA in as little as $10 \mathrm{pg}$ of genomic DNA 


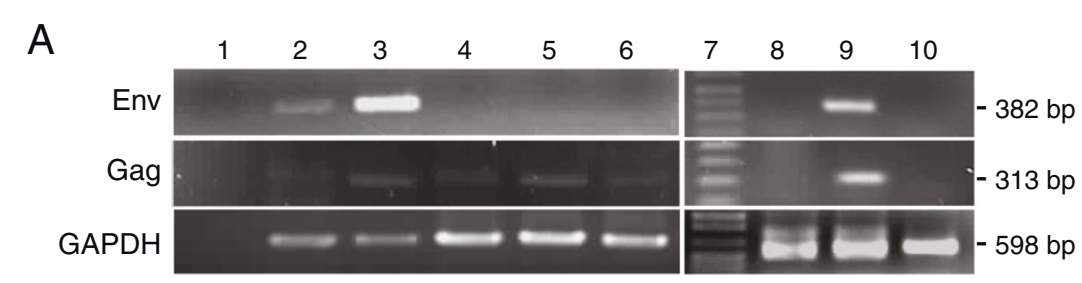

B
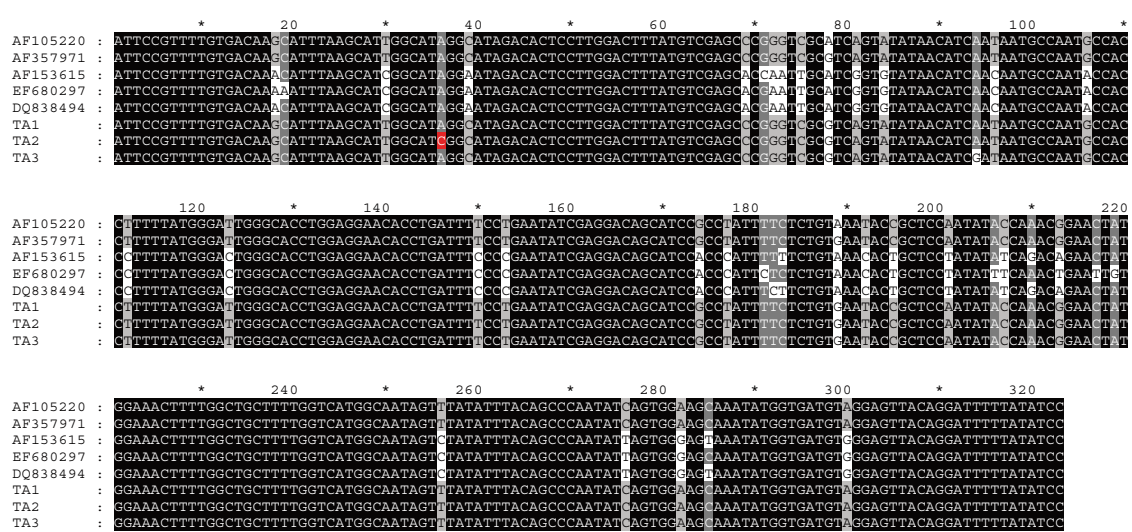

C

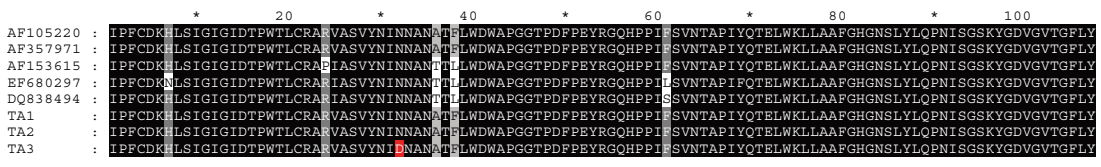

D
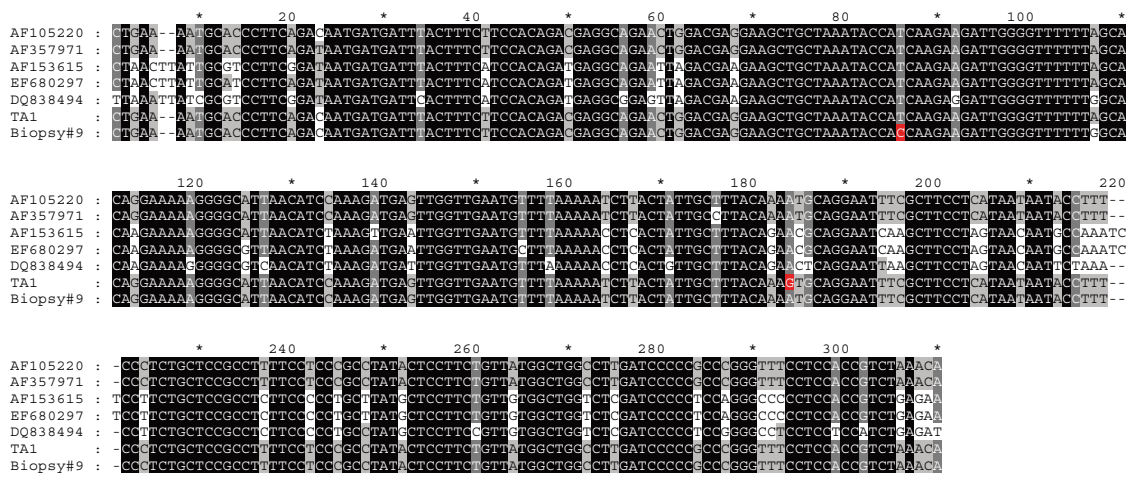

E

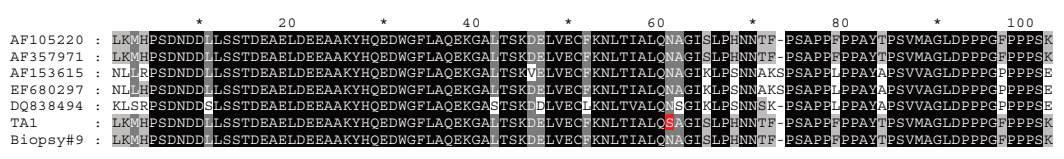

Figure 2 PCR amplification of JSRV env and gag sequences from genomic DNA. (A) Representative image of PCR products amplified using env- (upper panel), gag- (middle panel) and GAPDH-specific (lower panel) primers. Lanes 1; water only, 2; lung cancer tissue array - first round PCR, 3; lung cancer tissue array - second round PCR, 4; HBE135-E6E7, 5; A549, 6; nasopharyngeal cancer tissue array, 7; molecular weight marker, 8; non-neoplastic human lung, 9; OPA lung tumor cell line, JS7, and 10; normal sheep lung. Nucleotide (B) and amino acid (C) sequence alignment of PCR products amplified with env-specific primers. Nucleotide (D) and amino acid (E) sequence alignment of PCR products amplified with gag-specific primers. AF105220; accession number of the full-length JSRV genome deciphered by Palmarini et al. [12], AF357971; accession number of the full-length JSRV genome deciphered by De Martini et al. [39], AF153615; accession number of an endogenous JSRV genome deciphered by Palmarini et al. [40], EF680297 accession number of an endogenous JSRV deciphered by Arnaud et al. [41], DQ838494; accession number of a full-length JSRV genome of Chinese origin, TA; tissue array, Biopsy 9; adenocarcinoma in-situ \#9. 
(Figure 3A) while the nested PCR increased the sensitivity to less than $1 \mathrm{pg}$ of genomic DNA (Figure 3B). Although sheep mitochondrial DNA sequences were detected after the first round of PCR using 100 ng of genomic DNA isolated from the JS7 sheep lung tumor cell line (Figure 3C, lane 8), we were unable to detect any traces of sheep DNA in human DNA that tested positive for JSRV env or gag (Figure 3D, lanes 2-6), even after nested PCR.

\section{Discussion}

Here we demonstrate that a subset of human lung adenocarcinomas, squamous cell carcinomas and bronchioloalveolar carcinomas express an antigen that reacts with a JSRV Env specific monoclonal antibody in immunohistochemistry. Further, we demonstrate amplification of JSRV env and gag sequences from genomic DNA isolated from an array of pooled human lung cancer tissue samples as well as gag sequences from individual adenocarcinoma insitu samples. As with other studies, we did not find a strict correlation between adenocarcinoma in-situ and the presence of JSRV-like antigen. However, we did identify a
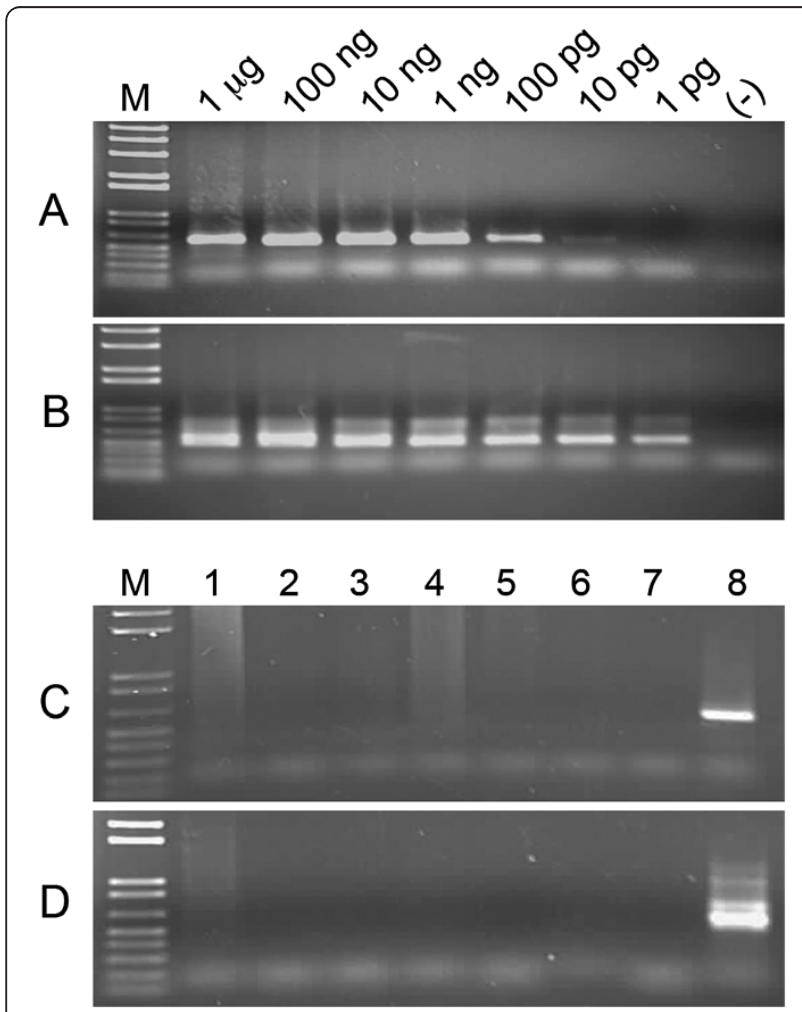

Figure 3 Absence of sheep mitochondria in human DNA samples. PCR (A) and nested PCR (B) of serial dilutions of sheep genomic DNA. First round PCR (C) and nested PCR (D) of genomic DNA isolated from non-neoplastic tissue (lane 1), lung cancer tissue array \#1 (lane 2), lung cancer tissue array \#2 (lane 3), lung cancer tissue array \#3 (lane 4), adenocarcinoma in-situ sample \#2 (lane 5), adenocarcinoma in-situ sample \#9 (lane 6), water (lane 7) and the OPA lung tumor cell line, JS7 (lane 8). M; marker. subset of adenocarcinoma and squamous cell carcinomas that were immunopositive suggesting that this association is broader than previously thought.

While immunohistochemical studies using JSRV Gag specific antibodies consistently identify $20-30 \%$ of human lung tumor samples as immunopositive $[26,27,30]$, the notion that a JSRV-like virus is associated with a subset of human pulmonary tumors remains controversial. In one study involving 249 human lung tumor samples, 30\% of adenocarcinoma in-situs, $26 \%$ of lung adenocarcinomas and two of seven large cell carcinomas were immunopositive for JSRV capsid protein [26], but subsequent attempts to detect genomic DNA or RNA using PCR and RT-PCR failed to detect JSRV gag sequences in human lung tumor samples [30]. Interestingly, a study of normal blood donors from Cameroon $(\mathrm{N}=44)$ and AIDS patients from Nigeria $(\mathrm{N}=20)$ detected orf- $x$ and gag-like sequences in $10 \%$ and $26 \%$ of whole blood specimens, respectively, but failed to detect JSRV-like sequences in a European cohort of 20 hemophiliacs, 15 blood donors, and 4 patients with adenocarcinoma in-situ or SCLC [27]. In our study, we employed a different approach and stained an array of human lung cancers with a highly specific monoclonal antibody against the oncogenic Env protein of JSRV, rather than Gag. The JSRV Env monoclonal antibody used in this study was produced against antigen that had been highly purified using affinity chromatography and highperformance liquid chromatography [35]. We cannot explain why our monoclonal antibody was able to detect JSRV Env-like antigens in human lung cancer specimens whereas a previous report using polyclonal antisera against JSRV Env was unsuccessful [29]; however, one possibility is that our monoclonal antibody is better at detecting denatured antigen. Interestingly, in that same study, 13/43 human lung adenocarcinomas that did not stain with antisera against JSRV Env, stained positive with both JSRV-CA and JSRV-MA antisera [29]. The fact that the JSRV Env monoclonal antibody did not crossreact with non-neoplastic lung tissue or nasopharyngeal carcinoma biopsies and only reacted strongly with a small subset of lung tumor samples suggests that the antibody is specific for an antigen present in human lung tumors. While we cannot rule out the possibility that the JSRV Env monoclonal antibody cross-reacts with an endogenous retroviral protein whose expression is upregulated in a subset of human lung tumors, our PCR data support the idea that the antigen detected by the JSRV Env monoclonal antibody is not simply a cross-reacting human protein.

It is important to note that the staining intensity and pattern in the TA differed somewhat from that of OPA (compare Figure 1F with Figure 1O). If a JSRV-like virus were to infect humans and initiate proliferation of lung epithelial cells, it is possible that the proliferating cells would be subject to immunoediting [43], which could 
potentially mutate Env and have an effect on the ability of the monoclonal antibody to recognize the JSRV Env-like protein. Interestingly, tumors that arise in transgenic mice expressing JSRV Env from an SPC promoter do not display uniform Env staining within the tumor and in some cases resemble the staining pattern seen in the TAs with grade 3 staining [24]. It is possible that if we had amplified the entire Env sequence we would have identified additional amino acid differences that might have resulted in modified glycosylation patterns and/or changes in epitope binding sites which could lead to decreased binding affinity of the monoclonal antibody.

In another study evaluating the presence of JSRV-like sequences in human lung tumors by PCR, geographical location was noted as an important factor. JSRV-like DNA was shown to be highly prevalent in Sardinian cases where sheep farming has been conducted for centuries and almost entirely absent in non-Sardinian cases from Campania, where sheep farming is largely non-existent [28]. Therefore, detection of JSRV-like DNA sequences in human lung tumors may be more likely in active sheep farming communities where there is an increased chance of human and sheep interaction. The same study also suggested that there could be a genetic component to determining the presence of JSRV in human populations as the isolated island population of Sardinia had higher rates of JSRV-like sequences among biopsies [28]. Interestingly, all of the human lung tumor biopsies and normal tissue included on the tissue arrays used in our study originated from China, the country with the largest sheep population worldwide (Food and Agriculture Organization of the United Nations) and where JSRV is endemic [44]. We also tested 10 adenocarcinoma in-situ and 10 normal human lung tissue samples from the USA, where OPA is uncommon. Two of the samples stained weakly positive for Env; however we were unable to consistently detect env by PCR. This is not surprising since the number of positively stained cells was relatively low and would have been assigned a staining intensity of 2 in accordance with our grading scheme. It is possible, therefore, that previous studies failed to identify JSRV DNA or RNA in human adenocarcinoma in-situ and lung adenocarcinoma cases because the samples were of US origin [30].

Occupational exposure to meat and live animals is a risk factor for developing lung cancer [45]. Persons who work in abattoirs where sheep, cattle, and pigs are slaughtered are exposed to livestock naturally infected with viruses that cause cancer in the animals. Included among this group of oncogenic viruses are JSRV and enzootic nasal tumor virus (ENTV). A recent study evaluating mortality and cancer incidence in two separate cohorts of workers from abattoirs $(\mathrm{N}=4996)$ and meat processing plants $(\mathrm{N}=3642)$, confirmed that there is an excess occurrence of cancer, particularly of the lung, in both abattoir and processing plant workers [33]. Similar results were previously reported for this and other related cohorts worldwide [34,46,47], suggesting that steps should be taken to protect workers from exposure to carcinogenic viruses in the workplace and that there could potentially be health implications for the general population which may also be exposed to some of these viruses. Interestingly, a recent report out of Europe suggests that professional exposure to goats increases the risk of pneumonic-type lung adenocarcinoma in humans [48].

\section{Conclusions}

The association between JSRV and human lung cancer is controversial; however, we have demonstrated the presence of an antigen that cross-reacts with a monoclonal antibody specific for the JSRV Env protein in human lung tumors and have amplified env- and gag-like sequences from these samples raising the possibility that JSRV could potentially contribute to lung tumorigenesis in humans. With high-throughput next generation sequencing approaches, a JSRV-like virus in human lung cancers may be identified which could have profound implications for prevention, diagnosis and therapy.

\section{Competing interests}

The authors declare that they have no competing interests.

\section{Authors' contributions}

NMLP, SRW and SKW performed the experiments. NMLP and SKW designed the studies. PNB and CM provided normal and BAC human samples and assisted with the histopathology. All authors contributed to drafting and editing the manuscript. All authors read and approved the final manuscript.

\section{Acknowledgements}

We thank Sheila Watson for her technical assistance. Special thanks to Dr. Jim Petrik for allowing us to use his laboratory for genomic DNA extractions and PCR amplifications and to Dr. Roger Moorehead and Darrick Yu for their assistance with grading the tissue arrays.

\section{Grant funding}

This work was supported by grant funding from the Natural Sciences and Engineering Research Council (NSERC) and the Canada Foundation for Innovation Leader's Opportunity Fund (CFI-LOF).

This work was supported by the Natural Sciences and Engineering Research Council of Canada (NSERC) and the Canada Foundation for Innovation Leader's Opportunity Fund (CFI-LOF). SRW was supported by an Ontario Veterinary College Graduate Fellowship.

\section{Author details}

'Department of Pathobiology, Ontario Veterinary College, University of Guelph, Guelph, Ontario N1G 2W1, Canada. ²Department of Pathology, Roswell Park Cancer Institute, Elm \& Carlton Streets, Buffalo 14263, New York, USA.

Received: 3 June 2013 Accepted: 13 March 2014

Published: 19 March 2014

\section{References}

1. American Cancer Society: Cancer facts and figures. 2013: [http://www cancer.org/research/cancerfactsfigures/cancerfactsfigures/cancer-factsfigures-2013]

2. Janssen-Heijnen ML, Coebergh JW, Klinkhamer PJ, Schipper RM, Splinter TA, Mooi WJ: Is there a common etiology for the rising incidence of and decreasing survival with adenocarcinoma of the lung? Epidemiology 2001, 12:256-258 
3. Gazdar AF, Linnoila Rl: The pathology of lung cancer-changing concepts and newer diagnostic techniques. Semin Oncol 1988, 15:215-225.

4. Maggiore C, Mule A, Fadda G, Rossi ED, Lauriola L, Vecchio FM, Capelli A: Histological classification of lung cancer. Rays 2004, 29:353-355.

5. Travis WD, Brambilla E, Noguchi M, Nicholson AG, Geisinger KR, Yatabe $Y$, Beer DG, Powell CA, Riely GJ, Van Schil PE, Garg K, Austin JH, Asamura H, Rusch W, Hirsch FR, Scagliotti G, Mitsudomi T, Huber RM, Ishikawa Y, Jett J, Sanchez-Cespedes M, Sculier JP, Takahashi T, Tsuboi M, Vansteenkiste J, Wistuba I, Yang PC, Aberle D, Brambilla C, Flieder D, et al: International association for the study of lung cancer/american thoracic society/european respiratory society international multidisciplinary classification of lung adenocarcinoma. J Thorac Oncol 2011, 6:244-285.

6. Raz DJ, He B, Rosell R, Jablons DM: Bronchioloalveolar carcinoma: a review. Clin Lung Cancer 2006, 7:313-322.

7. Cohen AJ, Pope CA 3rd: Lung cancer and air pollution. Environ Health Perspect 1995, 103(Suppl 8):219-224.

8. Nelson HH, Christiani DC, Wiencke JK, Mark EJ, Wain JC, Kelsey KT: k-ras mutation and occupational asbestos exposure in lung adenocarcinoma: asbestos-related cancer without asbestosis. Cancer Res 1999, 59:4570-4573.

9. Thun MJ, Lally CA, Flannery JT, Calle EE, Flanders WD, Heath CW Jr: Cigarette smoking and changes in the histopathology of lung cancer. $J$ Natl Cancer Inst 1997, 89:1580-1586.

10. McErlean A, Ginsberg MS: Epidemiology of lung cancer. Semin Roentgenol 2011, 46:173-177.

11. Sun S, Schiller JH, Gazdar AF: Lung cancer in never smokers-a different disease. Nat Rev Cancer 2007, 7:778-790.

12. Palmarini $M$, Sharp JM, de las Heras M, Fan H: Jaagsiekte sheep retrovirus is necessary and sufficient to induce a contagious lung cancer in sheep. J Virol 1999, 73:6964-6972.

13. Mornex JF, Thivolet F, De las Heras M, Leroux C: Pathology of human bronchioloalveolar carcinoma and its relationship to the ovine disease. Curr Top Microbiol Immunol 2003, 275:225-248.

14. Palmarini $\mathrm{M}$, Fan $\mathrm{H}$ : Retrovirus-induced ovine pulmonary adenocarcinoma, an animal model for lung cancer. J Natl Cancer Inst 2001, 93:1603-1614.

15. Perk K, Hod I: Sheep lung carcinoma: an endemic analogue of a sporadic human neoplasm. J Natl Cancer Inst 1982, 69:747-749.

16. Rai SK, Duh FM, Vigdorovich V, Danilkovitch-Miagkova A, Lerman Ml, Miller AD: Candidate tumor suppressor HYAL2 is a glycosylphosphatidylinositol (GPI)anchored cell-surface receptor for jaagsiekte sheep retrovirus, the envelope protein of which mediates oncogenic transformation. Proc Natl Acad Sci U S A 2001, 98:4443-4448.

17. Dirks C, Duh FM, Rai SK, Lerman MI, Miller AD: Mechanism of cell entry and transformation by enzootic nasal tumor virus. J Virol 2002, 76:2141-2149.

18. Caporale M, Cousens C, Centorame P, Pinoni C, De las Heras M, Palmarini M: Expression of the jaagsiekte sheep retrovirus envelope glycoprotein is sufficient to induce lung tumors in sheep. J Virol 2006, 80:8030-8037.

19. Allen TE, Sherrill KJ, Crispell SM, Perrott MR, Carlson JO, DeMartini JC: The jaagsiekte sheep retrovirus envelope gene induces transformation of the avian fibroblast cell line DF-1 but does not require a conserved $\mathrm{SH} 2$ binding domain. J Gen Virol 2002, 83:2733-2742.

20. Liu SL, Miller AD: Transformation of madin-darby canine kidney epithelial cells by sheep retrovirus envelope proteins. J Virol 2005, 79:927-933.

21. Maeda N, Palmarini M, Murgia C, Fan H: Direct transformation of roden fibroblasts by jaagsiekte sheep retrovirus DNA. Proc Natl Acad Sci U S A 2001, 98:4449-4454.

22. Danilkovitch-Miagkova A, Duh FM, Kuzmin I, Angeloni D, Liu SL, Miller AD, Lerman MI: Hyaluronidase 2 negatively regulates RON receptor tyrosine kinase and mediates transformation of epithelial cells by jaagsiekte sheep retrovirus. Proc Natl Acad Sci U S A 2003, 100:4580-4585.

23. Wootton SK, Halbert CL, Miller AD: Sheep retrovirus structural protein induces lung tumours. Nature 2005, 434:904-907.

24. Chitra E, Yu SL, Hsiao KN, Shao HY, Sia C, Chen H, Hsieh SY, Chen JH, Chow $\mathrm{YH}$ : Generation and characterization of JSRV envelope transgenic mice in FVB background. Virology 2009, 393:120-126.

25. Rai SK, De Martini JC, Miller AD: Retrovirus vectors bearing jaagsiekte sheep retrovirus Env transduce human cells by using a new receptor localized to chromosome 3p21.3. J Virol 2000, 74:4698-4704.

26. De las Heras M, Barsky SH, Hasleton P, Wagner M, Larson E, Egan J, Ortin A, Gimenez-Mas JA, Palmarini M, Sharp JM: Evidence for a protein related immunologically to the jaagsiekte sheep retrovirus in some human lung tumours. Eur Respir J 2000, 16:330-332.

27. Morozov VA, Lagaye S, Lower J, Lower R: Detection and characterization of betaretroviral sequences, related to sheep Jaagsiekte virus, in Africans from Nigeria and Cameroon. Virology 2004, 327:162-168.

28. Rocca S, Sanna MP, Leoni A, Cossu A, Lissia A, Tanda F, Satta MP, Palmieri G: Presence of Jaagsiekte sheep retrovirus in tissue sections from human bronchioloalveolar carcinoma depends on patients' geographical origin. Hum Pathol 2008, 39:303-304.

29. De Las HM, Murcia P, Ortín A, Azúa J, Borderías L, Alvarez R, Jiménez-Más JA Marchetti A, Palmarini M: Jaagsiekte sheep retrovirus is not detected in human lung adenocarcinomas expressing antigens related to the Gag polyprotein of betaretroviruses. Cancer Lett 2007, 258:22-30.

30. Yousem SA, Finkelstein SD, Swalsky PA, Bakker A, Ohori NP: Absence of jaagsiekte sheep retrovirus DNA and RNA in bronchioloalveolar and conventional human pulmonary adenocarcinoma by PCR and RT-PCR analysis. Hum Pathol 2001, 32:1039-1042.

31. Hopwood P, Wallace WA, Cousens C, Dewar P, Muldoon M, Norval M, Griffiths DJ: Absence of markers of betaretrovirus infection in human pulmonary adenocarcinoma. Hum Pathol 2010, 41:1631-1640.

32. Johnson ES: Cancer mortality among workers in the meat department of supermarkets. Occup Environ Med 1994, 51:541-547.

33. Johnson ES: Cancer mortality in workers employed in cattle, pigs, and sheep slaughtering and processing plants. Environ Int 2011, 37:950-959.

34. McLean D, Pearce N: Cancer among meat industry workers. Scand J Work Environ Health 2004, 30:425-437.

35. Wootton SK, Metzger MJ, Hudkins KL, Alpers CE, York D, DeMartini JC, Miller AD: Lung cancer induced in mice by the envelope protein of jaagsiekte sheep retrovirus (JSRV) closely resembles lung cancer in sheep infected with JSRV. Retrovirology 2006, 3:94.

36. Walsh SR, Linnerth-Petrik NM, Laporte AN, Menzies PI, Foster RA, Wootton SK: Full-length genome sequence analysis of enzootic nasal tumor virus reveals an unusually high degree of genetic stability. Virus Res 2010, 151:74-87.

37. Landen CN Jr, Lin YG, Immaneni A, Deavers MT, Merritt WM, Spannuth WA, Bodurka DC, Gershenson DM, Brinkley WR, Sood AK: Overexpression of the centrosomal protein Aurora-A kinase is associated with poor prognosis in epithelial ovarian cancer patients. Clin Cancer Res 2007, 13:4098-4104.

38. Liu SL, Duh FM, Lerman MI, Miller AD: Role of virus receptor Hyal2 in oncogenic transformation of rodent fibroblasts by sheep betaretrovirus env proteins. J Virol 2003, 77:2850-2858.

39. DeMartini JC, Bishop JV, Allen TE, Jassim FA, Sharp JM, de las Heras M, Voelker DR, Carlson JO: Jaagsiekte sheep retrovirus proviral clone JSRV (JS7), derived from the JS7 lung tumor cell line, induces ovine pulmonary carcinoma and is integrated into the surfactant protein $\mathrm{A}$ gene. J Virol 2001, 75:4239-4246.

40. Palmarini M, Hallwirth C, York D, Murgia C, de Oliveira T, Spencer T, Fan H: Molecular cloning and functional analysis of three type $D$ endogenous retroviruses of sheep reveal a different cell tropism from that of the highly related exogenous jaagsiekte sheep retrovirus. J Virol 2000, 74:8065-8076

41. Arnaud F, Caporale M, Varela M, Biek R, Chessa B, Alberti A, Golder M, Mura M, Zhang Y, Yu L, Pereira F, Demartini JC, Leymaster K, Spencer TE, Palmarini M: A paradigm for virus-host coevolution: sequential counter-adaptations between endogenous and exogenous retroviruses. PLoS Pathog 2007, 3:e170.

42. Hallwirth C, Maeda N, York D, Fan H: Variable regions 1 and 2 (VR1 and VR2) in JSRV gag are not responsible for the endogenous JSRV particle release defect. Virus Genes 2005, 30:59-68.

43. Schreiber RD, Old LJ, Smyth MJ: Cancer immunoediting: integrating immunity's roles in cancer suppression and promotion. Science 2011, 331:1565-1570.

44. Zhang K, Kong H, Liu Y, Shang Y, Wu B, Liu X: Diagnosis and phylogenetic analysis of ovine pulmonary adenocarcinoma in China. Virus Genes 2014 48:64-73.

45. Durusoy R, Boffetta P, Mannetje A, Zaridze D, Szeszenia-Dabrowska N, Rudnai P, Lissowska J, Fabianova E, Cassidy A, Mates D, Bencko V, Salajka F, Janout $\mathrm{V}$, Fevotte J, Fletcher T, Brennan P: Lung cancer risk and occupational exposure to meat and live animals. Int J Cancer 2006, 118:2543-2547.

46. Besson H, Banks R, Boffetta P: Cancer mortality among butchers: a 24-state death certificate study. J Occup Environ Med 2006, 48:289-293. 
47. Coggon D, Pannett B, Pippard EC, Winter PD: Lung cancer in the meat industry. Br J Ind Med 1989, 46:188-191.

48. Lutringer-Magnin D, Girard N, Cadranel J, Leroux C, Quoix E, Cottin V, Del Signore C, Lebitasy MP, Cordier G, Vanhems P, Mornex JF:

Professional exposure to goats increases the risk of pneumonic-type lung adenocarcinoma: results of the IFCT-0504-Epidemio study. PLOS One 2012, 7:e37889.

doi:10.1186/1756-0500-7-160

Cite this article as: Linnerth-Petrik et al: Jaagsiekte sheep retrovirus detected in human lung cancer tissue arrays. BMC Research Notes 2014 7:160

\section{Submit your next manuscript to BioMed Central and take full advantage of:}

- Convenient online submission

- Thorough peer review

- No space constraints or color figure charges

- Immediate publication on acceptance

- Inclusion in PubMed, CAS, Scopus and Google Scholar

- Research which is freely available for redistribution 